\title{
HUBUNGAN PENGETAHUAN TERHADAP PERILAKU CUCI TANGAN PETUGAS KESEHATAN DI BAGIAN ILMU KESEHATAN ANAK BLU RSUP PROF DR RD KANDOU MANADO
}

\author{
${ }^{1}$ Inayatur Rabbani S \\ ${ }^{2}$ Vivekenanda Pateda \\ ${ }^{2}$ Rocky Wilar \\ ${ }^{2}$ Novie H. Rampengan \\ ${ }^{1}$ Kandidat Skripsi Fakultas Kedokteran Universitas Sam Ratulangi Manado \\ ${ }^{2}$ Bagian Ilmu Kesehatan Anak Universitas Sam Ratulangi Manado \\ Email: inayatur_rabbanis@yahoo.co.id
}

\begin{abstract}
Health care-associated infection (HCAI) is defined as an infection occurring in a patient in a hospital or other health care facility in whom the infection was not present or incubating at the time of admission. This incident result in excess length of stay, mortality and healthcare costs. World Health Organization (WHO) has been campaigning the patient safety program, one of it is to lower the risk of HCAI. Wash hands to be one of the effective measures to break the chain of transmission of infection. Doctors, nurses and other hospital personnel must work together to ensure that hand washing before and after each contact with the patient, whether the patient known to be infected or not. The aim of this research is to find out the relationship between knowledge and health workers' hand washing behaviour in the department of child health at Prof dr RD Kandou Hospital Manado. This research was conducted using field survey design with observational analytic studies, in this case done by observation and questionnaires. The samples were 78. Conclusion: The result showed that from the 78 health workers there are 55 people who have poor knowledge about hand washing. As for health care workers with hand-washing behaviors are most numerous in the bad category amounted to 46 people. The results of the bivariate analysis showed the value of $p=0.160$. From the result it can be concluded that there is no significant relationship between knowledge and behavior of hand washing in healthcare workers in the department of child health at Prof Dr RD Kandou Hospital Manado.
\end{abstract}

Keywords: Knowledge, Behavior, Hand Washing, Hand Hygiene.

\begin{abstract}
Abstrak: Health care-associated infection (HCAI) didefinisikan sebagai infeksi yang terjadi pada pasien dalam rumah sakit atau fasilitas kesehatan lainnya dimana pada awalnya infeksi tersebut tidak hadir dan tanpa bukti inkubasi pada saat masuk rumah sakit. Kejadian ini menyebabkan lenght of stay (LOS), mortalitas, dan healthcare cost meningkat. World Health Organization (WHO) telah mengkampanyekan program keselamatan pasien salah satunya adalah menurunkan risiko HCAI. Cuci tangan menjadi salah satu langkah yang efektif untuk memutuskan rantai transmisi infeksi. Dokter, perawat dan personel lain rumah sakit harus bekerja sama untuk memastikan bahwa cuci tangan dilakukan sebelum dan sesudah setiap berkontak dengan penderita, apakah penderita diketahui terinfeksi atau tidak. Tujuan penelitian ini untuk mengetahui hubungan pengetahuan terhadap perilaku cuci tangan petugas kesehatan di Bagian Ilmu Kesehatan Anak BLU RSUP Prof Dr RD Kandou Manado. Penelitian ini dilakukan menggunakan desain survey lapangan dengan studi analitik observasional, dalam hal ini dilakukan dengan pengamatan dan pengisian kuesioner. Sampel berjumlah 78 orang. Simpulan: Dari hasil yang didapatkan dari 78 orang petugas kesehatan
\end{abstract}


terdapat 55 orang yang memiliki pengetahuan kurang baik tentang cuci tangan. Sedangkan untuk petugas kesehatan dengan perilaku cuci tangan paling banyak terdapat dalam kategori buruk berjumlah 46 orang. Hasil analisis bivariat menunjukkan nilai p=0,160. Dari hasil penelitian ini dapat disimpulkan bahwa tidak adanya hubungan yang bermakna antara pengetahuan dan perilaku cuci tangan petugas kesehatan di Bagian Ilmu Kesehatan Anak BLU RSUP Prof. Dr. RD Kandou Manado.

Kata Kunci: Pengetahuan, Perilaku, Cuci Tangan, Kebersihan Tangan.

Health care-associated infection (infeksi terkait perawatan) masih menjadi masalah utama dunia. Health careassociated infection (HCAI) didefinisikan sebagai infeksi yang terjadi pada pasien dalam rumah sakit atau fasilitas kesehatan lainnya dimana pada awalnya infeksi tersebut tidak hadir dan tanpa bukti inkubasi pada saat masuk rumah sakit. Infeksi ini terjadi baik di negara maju maupun negara berkembang. ${ }^{1}$ Sekitar 5\% dari semua anak yang masuk ke rumah sakit anak di Amerika Serikat (AS) mendapat $\mathrm{HCAI}^{2}$ Dalam pembelajaran kooperatif World Health Organization (WHO) (55 rumah sakit di 14 negara dari 4 wilayah WHO), sekitar 8,7\% dari pasien rawat inap mengalami HCAI. Kejadian ini menyebabkan lenght of stay (LOS), mortalitas, dan healthcare cost meningkat. $^{3,4}$

Petugas kesehatan mempunyai peran besar dalam rantai transmisi infeksi ini. ${ }^{4}$ World Health Organization (WHO) sebagai induk organisasi kesehatan dunia telah mengkampanyekan program keselamatan pasien salah satunya adalah menurunkan risiko HCAI. ${ }^{5}$ Cuci tangan menjadi salah satu langkah yang efektif untuk memutuskan rantai transmisi infeksi, sehingga insidensi HCAI dapat berkurang. ${ }^{4,6}$ Dokter, perawat dan personel lain rumah sakit harus bekerja sama untuk memastikan bahwa cuci tangan dilakukan sebelum dan sesudah setiap berkontak dengan penderita, apakah penderita diketahui terinfeksi atau tidak. ${ }^{2}$ Pelaksanaan cuci tangan dilakukan pada saat:

a. Sebelum dan setelah kontak langsung dengan pasien; b. setelah melepas sarung tangan;

c. sebelum memegang perangkat invasif (terlepas dari apakah sarung tangan digunakan atau tidak) untuk perawatan pasien;

d. setelah kontak dengan cairan tubuh atau ekskresi, membran mukosa, kulit yang tidak utuh, atau dressing luka;

e. jika berpindah dari bagian tubuh terkontaminasi ke bagian tubuh bersih selama perawatan pasien. ${ }^{4}$

Salah satu komponen standar kewaspadaan dan usaha menurunkan HCAI adalah menggunakan panduan kebersihan tangan yang benar dan mengimplementasikan secara efektif. ${ }^{5}$

Hand hygiene merupakan istilah umum yang berlaku baik untuk mencuci tangan, cuci tangan dengan antiseptik, maupun hand rub antiseptik. Pada tahun 1988 dan 1995, pedoman mencuci tangan dan antisepsis tangan diterbitkan oleh Association for Professionals in Infection Controls (APIC). ${ }^{6}$ Pada tahun 2009, WHO mencetuskan global patient safety challenge dengan clean care is safe care, yaitu merumuskan inovasi strategi penerapan hand hygiene untuk petugas kesehatan dengan My five moments for hand hygiene.

Sebuah penelitian oleh Larson dkk pada 40 rumah sakit angggota The National Nosocomial Infections Surveillance (NNIS) melaporkan kepatuhan tenaga kesehatan yang melakukan cuci tangan sebelum dan setelah kontak dengan pasien bervariasi antara $24 \%$ sampai $89 \%$, dengan rata-rata $56,6 \%$. Penelitian ini dilakukan setelah dipromosikannya program WHO dalam pengendalian infeksi. ${ }^{7}$ Menurut data Riset 
Kesehatan Dasar (RISKESDAS) tahun 2007, prevalensi nasional berperilaku benar dalam cuci tangan adalah $23,2 \%{ }^{8}$

\section{METODE PENELITIAN}

Jenis penelitian yang digunakan adalah survey lapangan dengan studi analitik observasional, dalam hal ini dilakukan dengan pengamatan dan pengisian kuesioner. Waktu penelitian dilakukan pada bulan November Desember 2013. Tempat penelitian dilakukan di Bagian Ilmu Kesehatan Anak BLU RSUP Prof Dr. RD Kandou Manado. Populasi adalah semua petugas kesehatan di Bagian Ilmu Kesehatan Anak. Sampel penelitian diambil berdasarkan kriteria inklusi yaitu : Terkait dengan perawatan pasien secara langsung pada hari diadakan penelitian, Bekerja hanya di Bagian Ilmu Kesehatan Anak BLU RSUP Prof Dr. RD Kandou Manado, Bersedia mengisi kuesioner. Variabel penelitian terdiri dari dua variabel diantaranya variabel bebas yaitu Pengetahuan petugas kesehatan tentang cuci tangan dan variabel terikat yaitu Perilaku cuci tangan.

Pengambilan data pengetahuan diperoleh dari kuesioner. Sedangkan data perilaku cuci tangan diperoleh dari lembar pengawasan. Analisis data dilakukan dengan uji chi square dengan menggunakan program SPSS.

\section{HASIL}

Tempat penelitian dilakukan di Bagian Ilmu Kesehatan Anak BLU RSUP Prof Dr. RD Kandou Manado. Untuk memperoleh gambaran distribusi menurut karakteristik responden dapat dilihat pada tabel berikut:

\section{Tabel 1. Distribusi responden} bedasarkan jenis kelamin

\begin{tabular}{ccc}
\hline $\begin{array}{c}\text { Jenis } \\
\text { Kelamin }\end{array}$ & N & $\begin{array}{c}\text { Persentase } \\
\mathbf{( \% )}\end{array}$ \\
\hline Laki-laki & 19 & 24,4 \\
Perempuan & 59 & 75,6
\end{tabular}

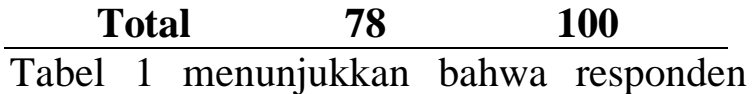
dengan jenis kelamin laki-laki yaitu berjumlah 19 orang, dengan persentase $24,4 \%$, sedangkan responden dengan jenis kelamin perempuan berjumlah 59 orang, dengan persentase $75,6 \%$,

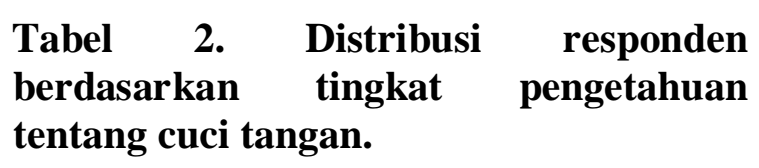

\begin{tabular}{ccc}
\hline Pengetahuan & N & $\begin{array}{c}\text { Persentase } \\
(\mathbf{\%})\end{array}$ \\
\hline Baik & 14 & 17,9 \\
Kurang Baik & 55 & 70,5 \\
Buruk & 9 & 11,5 \\
Total & $\mathbf{7 8}$ & $\mathbf{1 0 0}$ \\
\hline
\end{tabular}

Berdasarkan data hasil penelitian yang telah dilakukan jumlah petugas kesehatan dengan pengetahuan yang baik sebanyak 14 orang, dengan persentase 17,9 \%. sedangkan petugas kesehatan dengan pengetahuan kurang baik sebanyak 55 orang, dengan persentse $70,5 \%$, dan petugas kesehatan dengan tingkat pengetahuan buruk sebanyak 9 orang, dengan persentase 11,5 $\%$.

Tabel 3. Distribusi responden berdasarkan perilaku cuci tangan.

\begin{tabular}{ccc}
\hline Perilaku & N & $\begin{array}{c}\text { Persentase } \\
(\mathbf{\% )}\end{array}$ \\
\hline Baik & 13 & 16,7 \\
Kurang Baik & 19 & 24,4 \\
Buruk & 46 & 59 \\
Total & $\mathbf{7 8}$ & $\mathbf{1 0 0}$
\end{tabular}

Dari hasil penelitian terdapat 13 orang (16,7\%) dengan perilaku cuci tangan yang baik, 19 orang $(24,4 \%)$ dengan perilaku cuci tangan yang kurang baik, dan 46 orang (59\%) dengan perilaku cuci tangan yang buruk. 
Tabel 4. Hubungan pengetahuan terhadap perilaku cuci tangan petugas kesehatan.

\begin{tabular}{cccccc}
\hline $\begin{array}{l}\text { Pengeta } \\
\text { huan }\end{array}$ & Baik & $\begin{array}{c}\text { Perilaku } \\
\text { Kurang } \\
\text { Baik }\end{array}$ & Buruk & Total & $P$ \\
\hline Baik & 3 & 6 & 5 & 14 & \\
Kurang & 8 & 13 & 34 & 55 & 0,160 \\
Baik & & & & & \\
Buruk & 2 & 0 & 7 & 9 & \\
Total & $\mathbf{1 3}$ & $\mathbf{1 9}$ & $\mathbf{4 6}$ & $\mathbf{7 8}$ & \\
\hline
\end{tabular}

Setelah dilakukan hasil analisis bivariat antara pengetahuan dan perilaku cuci tangan, ternyata tidak diperoleh hubungan bermakna antara pengetahuan dan perilaku cuci tangan petugas kesehatan $(p=0,160)$.

\section{BAHASAN}

Berdasarkan data yang diperoleh, diketahui bahwa jumlah responden perempuan pada penelitian ini 59 orang (75,6\%) dan responden laki-laki berjumlah 19 orang $(24,4 \%)$.

Berdasarkan data hasil penelitian jumlah responden dengan tingkat pengetahuan paling banyak terdapat pada kategori kurang baik, sebanyak 55 orang (70,5\%). Sedangkan untuk perilaku cuci tangan dengan jumlah responden terbanyak terdapat pada kategori buruk, sebanyak 46 orang (59\%).

Pada tabel 4 dapat dilihat bahwa petugas kesehatan dengan pengetahuan baik lebih banyak melakukan perilaku cuci tangan dengan kurang baik dengan jumlah 6 orang. Begitu juga dengan petugas kesehatan dengan pengetahuan kurang baik, lebih banyak melakukan perilaku cuci tangan dengan buruk sebanyak 34 orang. Sehingga pada hasil uji chi square didapatkan hasil $p=0,160$, yang menunjukkan bahw $\mathrm{H}_{0}$ diterima, yaitu tidak terdapat hubungan (positif) antara pengetahuan dan perilaku cuci tangan petugas kesehatan di Bagian Ilmu Kesehtan Anak BLU RSUP Prof dr. RD Kndou
Manado. Hal ini berbeda dengan penelitian yang dilakukan oleh Rumapia $\mathrm{N}$ yang dilakukan pada perawat di Rumah Sakit Columbia Asia Medan menunjukkan bahwa perawat dengan tingkat pengetahuan baik tentang cuci tangan mempunyai tingkat kepatuhan cuci tangan yang lebih tinggi yaitu $73,75 \% .{ }^{9}$ Sedangkan berdasarkan hasil uji regresi logistik sederhana yang dilakukan oleh Damanik pada perawat di Rumah Sakit Immanuel Bandung, tidak didapatkan hubungan pengetahuan terhadap perilaku cui tangan dengan nilai $p=0,998 .^{10}$

Hasil pengetahuan yang kurang baik sebesar 70,5\% dan menjadi perilaku cuci tangan buruk sebesar 59\% juga dipengaruhi oleh kurangnya fasilitas cuci tangan yang memadai. Banyak hal yang dapat mempengaruhi perilaku cuci tangan yang baik, diantaranya status petugas kesehatan, yaitu non-dokter, dan juga pengenalan penggunaan handrub berbasis alkohol. Untuk meningkatkan pengetahuan petugas kesehatan mengenai cuci tangan diperlukan pelatihan mengenai pentingnya cuci tangan dan manfaatnya. ${ }^{5}$ Kesadaran dari petugas kesehatan juga dapat mempengaruhi perilaku dalam cuci tangan. Sedangkan untuk perilaku cuci tangan yang masih buruk, dapat dipengaruhi oleh kurangnya fasilitas cuci tangan yang baik dan berfungsi, seperti wastafel, kran air, sabun cuci tangan, dan handuk atau tisu kering. ${ }^{5,11}$

\section{SIMPULAN DAN SARAN}

Tingkat pengetahuan petugas kesehatan tentang cuci tangan terbanyak pada kategori kurang baik yaitu 55 orang (70,5\%). Tingkat perilaku cuci tangan petugas kesehatan terbanyak pada kategori buruk yaitu 46 orang (59\%). Dari hasil analisis bivariat data yang diperoleh melalui uji chi square menunjukkan nilai $\mathrm{p}=0.160(\mathrm{p}=<0.05)$ yang berarti data tidak signifikan. Ini menunjukkan bahwa tidak terdapat hubungan antara pengetahuan terhadap perilaku cuci tangan petugas 
kesehatan di bagian Ilmu Kesehatan Anak BLU RSUP Prof Dr RD Kandou Manado.

Perlu dilakukan penyuluhan dan sosialisasi mengenai cuci tangan. Perlu ditingkatkan lagi kesadaran petugas kesehatan terhadap pentingnya cuci tangan sebagai salah satu upaya pelayanan kesehatan yang aman untuk pasien dan dapat menurunkan risiko Health careassociated infection (HCAI). Penyediaan sarana cuci tangan seperti wastafel yang berfungsi dengan baik perlu ditambah agar perilaku cuci tangan dapat meningkat.

\section{DAFTAR PUSTAKA}

1. World Health Organization. Prevention of Hospital - Acquired Infection, a Practical Guide 2nd Edition. DoCDSa, penyunting. WHO/CDS/CSR/EPH/2002.12

[Diakses pada: 28 September 2013] Tersedia di: http://www.who.int/csr/resources/p ublications/drugresist/WHO_CDS CSR_EPH_2002_12/en/

2. Arvin AM. Pengendalian Infeksi. Dalam: Behrman RE, Kliegman R, Arvin AM, Wahab AS, penyunting. Ilmu Kesehatan Anak Nelson, Volume 2. Edisi 15. Jakarta: EGC; 2000. h. 1266-7.

3. Custodio HT. Hospital - Acquired Infections. eMedicine; 2007 [Diakses pada: 28 September 2013] Tersedia di: http://emedicine.medscape.com/arti cle/967022-overview

4. World Health Organization. WHO Guidelines on Hand Hygiene in Helath Care (Advanced Draft): A Summary.
WHO/EIP/SPO/QPS/06.2. 2006

[Diakses pada: 28 September 2013]

Tersedia

di:

http://www.who.int/patientsafety/e vents/05/HH_en.pdf

5. World Health Organization. WHO Guidelines on Hand Hygiene in Health Care: First Global Patient Safety Challenge Clean Care is Safer Care; 2009.

6. Boyce JM, Pittet D. Guidline for Handhygiene in Health-Care Settings. Morbidity and Mortality Weekly Report. 2002;51:1-44.

7. Larson EL, Quiros D, Lin SX. Dissemination of the CDC's Hand Hygiene Guideline and Impact on Infection Rates. Am J Infect Control. 2007;35: 666-75.

8. Badan Penelitian dan Pengembangan Kesehatan. Departemen Kesehatan. Riset Kesehatan Dasar (RISKESDAS). 2007. Jakarta: Departemen Kesehatan RI.

9. Rumapia, N. Hubungan Karakteristik Perawat dengan Tingkat Kepatuhan Perawat Melakukan Cuci Tangan di Rumah Sakit Columbia Medan. Medan: Universitas Darma Agung Medan; 2011.

10. Damanik, SM. Kepatuhan Hand Hygiene di Rumah Sakit Immanuel Bandung. Bandung: Universitas Padjajaran; 2012.

11. World Health Organization. WHO Guidelines on Hand Hygiene in Health Care: a Summary, First Global Patient Safety Challenge Clean Care is Safer Care; 2009. 